Synthesis, part of a Special Feature on Public policies and management of rural forests: lasting alliance or fool's dialogue?

\title{
The Multiple Dimensions of Rural Forests: Lessons from a Comparative Analysis
}

\author{
Didier Genin ${ }^{1}$, Yildiz Aumeeruddy-Thomas $^{2}$, Gérard Balent $^{3}{ }^{\text {and Robert Nasi }}{ }^{4}$
}

\begin{abstract}
Rural forests are characterized by different levels of formal and nonformal appropriation by rural communities who have generally managed, shaped, or rebuilt these forest formations over many generations with refined local knowledge and practices related to their use and perpetuation. Rural forests are therefore social-ecological systems that contribute to ecosystem and landscapes configuration, definition of rural territories, and sustainability of local livelihoods. Although some studies have attempted to explain their specificities, in specific geographical and social contexts, their characteristics are not well defined as they encompass highly diversified situations. This lack of comprehension of the identity of rural forests is at the heart of the lack of dialogue between forestry policies and rural forest development. Our major aim is to identify universal characteristics of rural forests as well as specificities that can differentiate them. Eleven situations of rural forests were analyzed by means of detailed, harmonized monographs, from developing and developed countries, and localized within contrasting ecological environments (humid tropics, dry forests, temperate forests) and socio-economic and public policies contexts. Qualitative data were obtained through a common analytical framework and were encoded with an approach based on the collective appreciation of the group of researchers who developed case studies. These were pooled within a common analysis chart and were processed by means of multivariate analyses. Results were further discussed taking into consideration four major characteristics that emerged from this analysis, and which form the identity of rural forests. These are: 1) specific forest structures and levels of integration in agricultural matrices which are linked historically to overall agroecosystem approaches and practices, 2) a multiscale approach to domestication practices from landscape to individual trees inscribed in continuities between "nature" and "culture", natural processes and human techniques of control and transformation, 3) multiple uses of plant species which vary in relation to the commercial or noncommercial status of their products and a reversible nature of these use patterns accordingly, 4) the imbricate nature of rules of access and control between state and customary levels, and between individual and collective levels, requiring specific formal and informal arrangements. Typologies of rural forests can be drawn along each of these major characteristics and provide a reliable system to analyze and understand the functioning of rural forests. Forestry approaches in rural contexts, hence, need to consider variations along these major lines that form the identity cards of rural forests.
\end{abstract}

Key Words: local practices and knowledge; multiple uses; multivariate analyses; state and customary rules; rural forests;

\section{INTRODUCTION}

Managing tree and forest resources is a vital component for sustaining rural livelihoods and agricultural activities worldwide (Pretzsch 2005) not just in developing countries, but also in traditional or innovative situations in developed countries (Balent 1996, Ni Dhubhain et al. 2009). Indeed, the importance of rural forests for local societies, from both archeological and socio-anthropological perspectives, has long been recognized (Descola 1986, Heckenberger et al. 2003). Since the beginning of the 1970 s scholars have acknowledged the relevance of rural forestry models for forest science, conservation, and development. In practice, however, the diversity of knowledge, know-how, practices, and strategies, as well as the socio-political dimensions that have sustained these practices, remain poorly recognized by public agricultural and forestry policies. This may be due to the absence of a clear picture of the unity and diversity of such systems and the lack of an overview of major driving forces. Few comparisons of empirical case studies, based mainly on regional geographic scales, have explored the nature and intrinsic characteristics of rural forests (Michon et al. 2007). Those that have done so employ terms such as: indigenousor community-managed forests (Wiersum 1997), farmer forests (Balent 1996), anthropogenic forests (Peluso 1996), agroforests (Michon and de Foresta 1999), intermediate forest systems (Angelsen et al. 2000) or domestic forests (Michon et al. 2007). This plethora of terms makes it difficult for a simple definition of these wooded areas that are governed with more or less strong interactions by local human communities. More, what has to be considered as 'forest' remains questioned, according to academic backgrounds and broad regional conceptions (tropical forestry, semi-arid areas, etc.). However, all these previous studies point out three common factors: the adaptability of these forest-based systems to various local, social, and ecological conditions; the range of specific forestry or agricultural-based practices differing from formal forestry approaches; and the importance of the socio-political dimension in their construction. By the term "rural forest", we refer to wooded areas that, in their diversity, are more or less formally managed, shaped, transformed, or rebuilt by rural

${ }^{1}$ IRD, Laboratoire Population, Environnement, Développement, France, ${ }^{2} \mathrm{CNRS}$, Centre d'Ecologie Fonctionnelle et Evolutive, France, ${ }^{3}$ INRA, UMR DYNAFOR, Université de Toulouse-INRA, France, ${ }^{4} \mathrm{CIFOR}$, Indonesia 
individuals or communities; that are fully integrated within farming systems; and that constitute an important structuring component of rural landscapes, territories, and production systems (Balent 1996, Michon et al. 2007, Genin et al. 2010). They always include a significant spontaneous treecomponent that is conserved, managed, or even favored by local people; they can also integrate additional tree plantations, but embrace different structures from artificial groves or gardens planted with trees. Therefore two main questions arise: Can these tree-based ecosystems connected to humans be globally defined? Can we advance key indicators of their drivers to provide some insights into a new social ecological approach to forestry?

We propose to characterize rural forests using a common analytical approach of contrasted situations that identifies factors and social or ecological aspects that universally define rural forests, as well as factors and aspects that relate to specific conditions. Through the association of several experienced teams working in five contrasted countries, the POPULAR research project (Public policies and management of rural forests: lasting alliance or fool's dialogue?) provided the opportunity to jointly analyze a set of these types of forests, by bringing together interdisciplinary experiences from northern- and southern-hemisphere countries covering different eco-climatic areas (tropical, temperate, semi-arid), and by using a common analytical framework based on multivariate and qualitative analysis, developed within the project.

\section{MATERIAL AND METHODS}

Empirical data was provided by 11 case studies covering a large array of ecological conditions (humid tropical forest, dry forests, and temperate forests) as well as socio-political environments (human population pressures, socioeconomic conditions, and public policies). The choice of these case studies was not driven by an ex ante selection based on explicit criteria, rather, the diversity of rural forest types brought by project participants seemed sufficient to explore the make-up of their global identity and specificities. For more precise descriptions and analyses of these cases, the reader can refer to other papers in (Nasi et al. 2013), or to the POPULAR project website (http://www.add-popular.org).

Five cases refer to temperate rural forests in France. These rural forests, managed by farmers, contrast with the rather centralized management of public forests which has prevailed in France for centuries (and still prevails). The modernization of agriculture in the second half of the $20^{\text {th }}$ century has strictly separated agriculture from forestry and has boosted rural transformation, especially through rural exodus. The French cases are illustrated by:

- multifunctional small-scale forests managed for centuries as an integral component of local family farms in Gascony (south-west France) (Deconchat et al. 2007, Sourdril et al. 2012).

- the revival of domestic chestnut forests (Castanea sativa) in Corsica and its complex evolution within a constantly adverse political environment (Michon and Sorba 2010, Michon 2011).

- the resilience of chestnut forest-orchards in Cevennes (south of France), which experienced several phases of abandonment and renovation, building upon social-ecological legacies, knowledge, know-how and innovations as well as institutional change (Aumeeruddy-Thomas et al. 2012).

- the multifunctional ash tree (Fraxinus excelsior), traditionally attached to Pyrenean farms, evolving into an invasive species in the abandoned highland pastures (southwestern France) (Julien et al. 2006).

- the truffle - holm oak associations (Tuber melanosporum Quercus ilex associations) in the Languedoc garrigues, a closed-forest resulting from the abandonment of former silvopastoral practices where local initiatives have emerged to revive truffle woods and to establish new additional oak plantations (Aumeeruddy-Thomas et al. 2012).

Two cases highlight semi-arid rural forests in Morocco: the forest 'agdal' in the High Atlas mountains (mixed holm oak [Quercus ilex], and three species of juniper forests), a customary community-based forest management practice based on limited access to the forest on a temporal basis (Hammi et al. 2010, Auclair et al. 2011); and the argan (Argania spinosa) forest, a unique inhabited native forest (south-west Morocco) facing the consequences of the sudden success of argan oil in international markets (Simenel et al. 2009, Genin and Simenel 2011).

The Southern Cameroon case study illustrates the evolution of local tropical humid forest management systems in the face of an emerging 'community forests' policy (Lescuyer et al. 2012).

The Indian (Western Ghats) case illustrates the complexity of forester/farmer relationships in a tropical humid forest mosaic. Here, privately-owned agroforests and commonly-managed sacred forests coexist with reserved forests transferred to local people under Joint Forestry Management schemes defined by forestry services (Hinnewinkel et al. 2008, Macura et al. 2011). Due to the high diversity found in this region, the analysis distinguished two situations - agroforests and reserved forests - as two separate case studies.

The Indonesian case studies illustrate use and management of tropical humid agroforests and forest resources by communities in a context of rapid changes in land access, forestry practices and conservation policies (Feintrenie et al. 2010). 
Detailed monographs, characterizing local forests as socialecological systems, were developed for each site by different members of the POPULAR team through an interdisciplinary approach. These took into account stakeholders, natural resources allowance, practices, policies, and ecological dynamics. To ensure the data collected were comparable, the monographs followed a common analysis grid focusing on five main themes: 1) physical and ecological characteristics; 2) actors and use rules; 3) uses and functions of forest resources; 4) naturalist, technical, organizational, spiritual, and political knowledge linked to trees and forests; 5) main social and ecological dynamics and challenges related to forested areas.

As a first step, case study monographs were analyzed collectively and global similarities or differences were pointed out by a qualitative interactive analysis conducted by the authors. All researchers involved in the POPULAR project then discussed the case study comparisons. This collective approach enabled the whole team to adjust its common understanding of the different case studies, identifying common or distinct features. As a second step, drawing on this material and researchers' expertise, we built a comparative database; it featured 58 variables referring to the five main themes noted above (Table 1).

We rated the outcomes for each variable on a five-point scale: nonexistent or very low (1); low or of little importance (2); neutral or average importance (3); high or important (4); and very high or very important (5). The codified results were then discussed with all POPULAR team members who had generated the individual monographs. This participative process stimulated discussions, facilitated consistent and comparable information, and resulted in a coconstruction of the comparative scoring of the variables for each rural forest case. All the variables of the resulting contingency table were treated as having uniform weight, and were analyzed together through Multiple Correspondence Analysis (MCA) (Benzecri 1973). We performed MCA in two stages: reducing global diversity of data set into a few number of dominant factors (axes) reflecting the main gradients structuring the data; and grouping all the studied cases into a few number of types from their scores along the 4 main axes. This analysis provided a nonparametric description of the relationships between modalities of variables and an indication of their importance rather than a measure of significance. This made it possible for us to treat both qualitative and quantitative data alike. We performed a Hierarchical Cluster Analysis of both variables and case studies on the basis of their scores along the four main significant MCA axes, and using Euclidian distance and Ward linkage functions. The Pearson correlation test was used to evaluate similarities between sites, as well as clusters of variables resulting from the cluster analysis. Data treatments were carried out using STATBOX software.

\section{RESULTS}

\section{Multidimensional aspects of rural forests: toward a global characterization}

The multidimensional analyses enabled us to differentiate categories of rural forests according to different social and ecological characteristics. The first four MCA axes covered more than $65 \%$ of the total variance, which is a relatively high score for a qualitative data set (Table 2). Based on the scores of both variables and sites along the main MCA axes, major similarities and differences are as follows (Fig. 1).

With respect to variables, axis 1 opposes forests with high species diversity, tree cover, multiple uses, low level of tree domestication and strong collective rules against forests with low species diversity, highly transformed ecosystems, high landscape fragmentation, strong private ownership and historical changes in social systems (institutions, land and know-how transmission, commercial circuits). With respect to forest sites, axis 1 opposes tropical humid rural forests (Cameroon, Indian reserved forests and Indonesian agroforests) against Mediterranean and temperate rural European (French) forests. These differences could be the result of biogeographical factors (tropical areas versus Mediterranean and temperate ones), sociopolitical factors (institutions, for example collective versus individual; and policies, for example centralized versus private) and historical factors.

With respect to variables, axis 2 opposes small forest patches with private ownership, strong compliance to collective rules, poor economic functions and fragmented landscapes against mixed ownership (private, collective, and public), strong collective rules, as well as state rules, and use of nontimber forest products (NTFPs), and poor landscape fragmentation. Sites implicated are the small private forests of Gascony, the ash tree forests of the Pyrenees and Indian reserved forests versus Moroccan argan forest and Indonesian agroforests.

With respect to variables, axis 3 opposes historically settled forest domestication or strong transformations at the tree-stand level, low influence of actors promoting sustainable development, little transformation of traded forest products and a low level of consumption at household level against strong domestication practices at the individual tree and tree population level, importance of animal husbandry (contributing also to transformation of the whole ecosystem), deep transformations of practices and social systems, transformation and trade of forest products and the importance of new actors promoting sustainable development. With respect to forest sites, the third axis opposes the small private forests of Gascony and the new silvicultural and plantation practices of the truffle - holm oak system against the Corsican and Cevennes chestnut forests, reflecting the important rural forest variability within France due to highly diverse sociopolitical trajectories and ecological conditions. 
Table 1. List of the 58 variables conforming the database for characterization of rural forests

Ecological characterization Ecosystem transformation

Ecosystem stability

Antiquity of uses

Tree domestication

Tree stand domestication

Landscape domestication

Forest fragmentation

Forest ratio

Tree species diversity

Tree cover

\section{Stakeholders, Rules}

Importance of individual stakeholder in forest management

Importance of collective institutions in forest management

Non formal collective actions

Importance of the state in forest management

New interveners/stakeholders in Sustainable

Development

New interveners/stakeholders not linked to

Sustainable Development

Overt conflicts between public policies and local stakeholders

User's rights restrictions imposed by the state

Existence of collectively developed user's rules on forest resources

Respect of users' restrictions by stakeholders

Control of uses by state

Control of collective uses rules

Collective forest land tenure

Private forest land tenure

State forest land tenure

Uses and functions

Timber

Firewood

Browsing, tree forage

Non Timber Forest Products (NTFP)

Agriculture

Tourism

Sacred character

Multiple uses

Trading functions

Self-consumption functions

Reserve/security functions

Marking territory functions

Patrimony functions

Identity functions
Indicates to which extent man-induced practices have modified natural environment Indicates ecological dynamics currently observed

Indicates the history of use of the forest

Indicates direct human intervention on individual trees (selection of varieties, intentional pruning, etc.)

Indicates management of tree stand (height homogeneity, types of individuals)

Indicates the level of anthropic transformation of the overall landscape

Indicates the level of forest scattering within the landscape

Indicates the importance of forested areas

Indicates the species richness of the forest (with respect to the average found in the region)

Indicates the role of individual stakeholders in forest management

Indicates the role of collective institutions (traditional, formally constituted, etc.) in forest management

Indicates collective action relative to forest management outside of formal recognition Indicates the role of state services in forest management

Indicates the presence and importance of stakeholders claiming sustainable

development actions (environmental associations, authorized firms, etc.)

Indicates the presence and importance of new stakeholders outside the SD sphere

(private commercial firms, etc.)

Indicates conflicting claims for the use of forests

Indicates the degree of freedom given to stakeholders by public policies

Indicates if user's rules have been developed collectively within local communities

Indicates if uses restrictions (whatever the origin) are actually followed by stakeholders Indicates if there is an effective control of uses rules at national level

Indicates if there is an effective control of the rules at community level

Collectively owned forests

Individually owned forests

State owned forests
Indicates if agricultural activities are performed in the forest (crops, groves, plantations, rangelands, etc.)

Implication of forests in tourism activities

Indicates if forests hold a special place and meaning in the local cosmogony (sacred areas, sacred trees, etc.)

Indicates diversity in forest resources uses

Indicates if forests are generating commercial/trading incomes

Indicates the importance of forest resources for household self-consumption

Indicates an eventual role of forests as resource for emergency events (emergency

forage, or foods in case of extreme climatic events for example)

Indicates an eventual role of forests in dividing the territory in differentiated plots

Indicates the patrimonial dimension attributed to forests (place of forest in

representation systems, transmission, and family or lineage heritage)

Indicates the place of forests in the identity of local communities

Knowledge, know-how, practices 
Traditional naturalist knowledge in forest management

Tree-related knowledge

Tree stand-related knowledge

Landscape knowledge

Know-how on transformation of forest products Know-how on valorization of forest products Organizational know-how

Political know-how

Dynamics, changes and stakes

Regression of forested areas

Increase of forested areas

Observed changes of forest uses and management

Exogenous origins of these changes

Observed s transformations of social systems

Stakes concerning biodiversity

Stakes concerning erosion, and water and soil conservation

Forest-agriculture integration

Forest-other activities integration

Stakes concerning local territory construction and securitization

Economical stakes

Social stakes
Indicates the extent of traditional knowledge involved in the management of forests

Indicates the extent of common held knowledge related to individual trees (type of pruning, level of extraction pressure, etc.)

Indicated the extent of common held knowledge related tree stands (tree density, tree conduct, etc.)

Indicates the extent of common held knowledge related to landscape (connectivity, exposition arrangement, ecosystem interactions, etc.?)

Indicates if local communities have developed collective mechanisms for differentiation and valorization of forest resources uses

Indicates if local communities have developed political relays to convey their opinion concerning forest management

Indicates if local communities are undergoing transformation in their social functioning

Indicates the level of integration of forestry and agricultural activities

Indicates the level of associations of forestry activities and other activities, such as tourism, environmental protection, etc.

Indicates if forests are the objects of territorial stakes at local level
Table 2. Contributions of the case studies to the first four axes (F1 to F4) provided by the Multiple Correspondence Analysis (MCA). -- or ++ means a highly significant contribution to the axis $(\mathrm{p}<0.01)$

\begin{tabular}{lllll}
\hline \hline & $\mathrm{F} 1$ & $\mathrm{~F} 2$ & $\mathrm{~F} 3$ & $\mathrm{~F} 4$ \\
\hline $\begin{array}{l}\text { Percent of total } \\
\text { variance }\end{array}$ & 21,9 & 18,8 & 15,1 & 12,3 \\
High Atlas & 6,20 & 0,13 & 4,86 & $31,87--$ \\
Argan Forest & 2,64 & $20,36--$ & 3,04 & 4,15 \\
Corsica & $14,46--$ & 3,53 & $13,10--$ & 2,06 \\
The Cevennes & $11,79--$ & 3,79 & $11,44--$ & 0,83 \\
Gascony & 2,42 & $18,39++14,04++$ & 2,16 \\
Indonesia & $7,75+$ & $11,82--$ & 1,20 & 0,77 \\
Truffles & $13,07--$ & 3,51 & $39,08++$ & 2,49 \\
Indian AgroForest & 0,11 & 1,99 & 0,25 & $47,73++$ \\
Indian Reserved & $14,04++18,38++6,11$ & 5,83 \\
Forest & & & & \\
Pyrenees Ash tree & 6,32 & $18,05++$ & 6,88 & 0,38 \\
Cameroon & $21,20++$ & 0,05 & 0,00 & 1,72 \\
\hline
\end{tabular}

With respect to variables, axis 4 opposes strong collective land ownership status and well-defined, highly respected use rules (Moroccan forest agdal also characterized by a heavy use of foliage as fodder, and an important role as reserve/safety in cases of climatic hazards) against forests with high integration of cultivation, the use of NTFPs and strong political knowhow, suggesting a structured local organization relating to forest management, namely the Indian agroforests.
Fig. 1. Representation of the 11 case studies of rural forests and some significant modalities of variables on the F1XF2 plan of the MCA. F1 and F2 are linear combinations provided by the MCA, which cover 22 and $19 \%$ of the total variance, respectively. Stars represent case studies; bullets represent main significant variables conforming these two axes

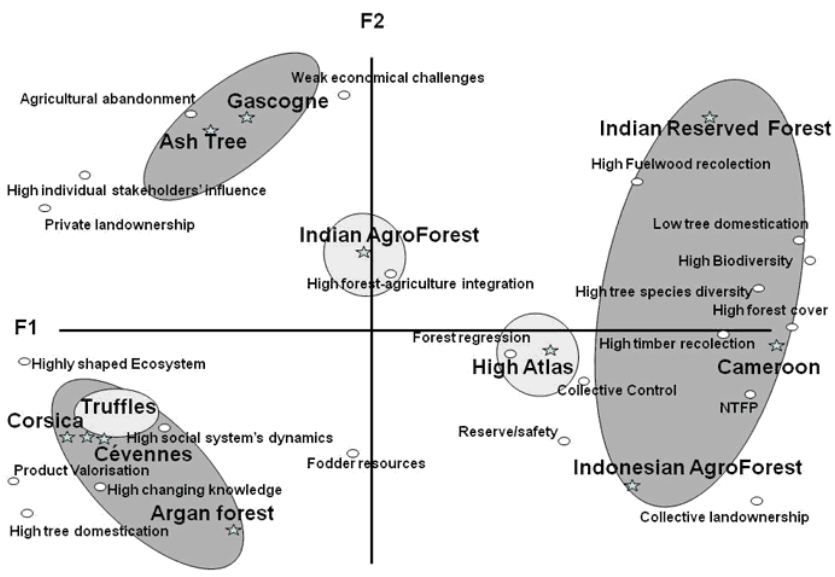


The Hierarchical Clustering Analysis of the forest sites provides five distinct groups (Fig. 2): High Atlas (group 1); Cameroon, Indonesia, Indian reserved forests (group 2); Indian agroforests (group 3); French Corsica and Cevennes chestnut forests, Moroccan argan forest (group 4); and French Gascony private forests, truffle - holm oak associations, and ash tree forests (group 5).

Fig. 2. Cluster Analysis of the 11 case studies of rural forests

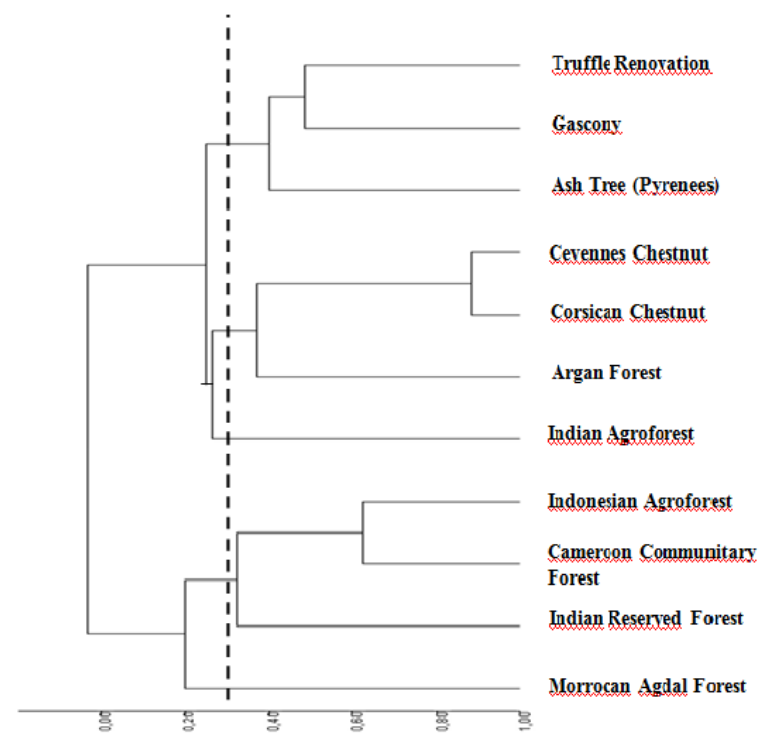

The analysis points out similarities in tropical humid forests worldwide (group 2); forests with a single tree species that structures the forest ecologically and socially (chestnut forests, argan forests) (group 4); and forests with a traditional forest and tree management found in France, mainly characterized by almost completely private decisions and practices, with very weak external interventions (group 5). There are two individual cases: the agdals in Morocco's High Atlas mountains, where strong traditional collective rules and uses highly impact the overall forest management; and Indian agroforests, with their mix of individual, collective, and state interventions, and a high diversity within the transect between natural and highly transformed forest.

The Hierarchical Clustering Analysis of the variables provided seven distinctive classes (see Appendix):

- Classes 1 and 3 variables are characteristic of group 4 forest sites (Corsica, Cevennes, argan forest). They correspond to rural forests based on the use of a single tree species (chestnut or argan) for which knowledge related to control and domestication are important, as well as practices of transformation and value-added products.

- Class 2 variables are characteristic of group 5 forest sites (Gascony, truffle, ash tree). These variables represent the typical French small-scale forests: integrated into traditional farming systems, relatively untouched by forest public policies and managed at the family level to meet various needs and amenities (timber and firewood, mushrooms, hunting places, etc.).

- Class 4 variables are common characteristics of all rural forest types: multiple-use, home consumption, importance of wood (firewood and timber), tree species diversity, ecosystem stability and important patrimonial functions as well as roles in the construction of territories.

- Class 5 variables are all the major characteristics relevant to tropical rural forest sites (groups 2 and 3), showing the importance of timber, high biodiversity and the use of various NTFPs (resins, fruits, medicinal plants, etc.).

- Class 6 variables link traditional rural forests found in developing countries (groups 1,2, and 3), where the influence of diversified collective institutions (customary or more or less legally formalized) is critical to the management of forest areas, and where these areas have important functions as reserves/safety nets for livelihoods.

- Class 7 variables reflect the strong influence of state-level management and control of rural forests, which strongly influences relations between local populations and their forests [High Atlas (group 1) and Indian reserved forests (group 3)].

\section{Diversity and complexity of social ecological relationships in rural forests as a mark of identity: four angles of analysis}

Both the MCA and the cluster analysis enabled us to filter and compare the high diversity of studied rural forest situations. The main characteristics of rural forests could be organized around four main themes: 1) multiple uses as a general feature of rural forests; 2) the question of forest and agricultural land divide; 3 ) the fuzzy border between forest domestication and transformation; and 4) the implications of land access and control as well as forest policies.

Multiple uses - a general feature of rural forests

All cases examined confirm the multiple uses of forest products and environments within rural forests. Multiple uses involve intricate linkages between gathering wild products, favoring regeneration of specific resources and cultivating others. 
Table 3. Diversity of uses in the 11 rural forests under study

\begin{tabular}{|c|c|c|c|c|c|c|c|c|c|c|c|c|c|c|}
\hline & \multicolumn{3}{|c|}{ Ligneous products } & \multicolumn{6}{|c|}{ Non timber forest products } & \multicolumn{5}{|c|}{ Activities in forested areas } \\
\hline & Timber & Handicraft & Firewood & $\begin{array}{c}\text { Fruits } \\
\& \\
\text { nuts }\end{array}$ & $\begin{array}{l}\text { Fodder } \\
\text { foliage }\end{array}$ & Medicine & Cosmetics & $\begin{array}{l}\text { Human } \\
\text { aliment }\end{array}$ & Mushroom & Rituals & $\begin{array}{l}\text { Hunting } \\
\text { fishing }\end{array}$ & Grazing & Crops & Leisure \\
\hline High Atlas & $\mathrm{X}$ & & $\mathrm{X}$ & & $\mathrm{X}$ & & & & & $\mathrm{X}$ & & $\mathrm{X}$ & & \\
\hline $\begin{array}{l}\text { Argan } \\
\text { forest }\end{array}$ & $\mathrm{X}$ & & $X$ & $X$ & $X$ & & $\mathrm{X}$ & $\mathrm{X}$ & & $X$ & & $X$ & $\mathrm{X}$ & \\
\hline $\begin{array}{l}\text { Reserved } \\
\text { forest } \\
\text { India }\end{array}$ & $\mathrm{X}$ & $\mathrm{X}$ & $\mathrm{X}$ & $\mathrm{X}$ & $\mathrm{X}$ & $\mathrm{X}$ & & $\mathrm{X}$ & & $\mathrm{X}$ & $\mathrm{X}$ & & & \\
\hline $\begin{array}{l}\text { Indian } \\
\text { agroforest }\end{array}$ & $\mathrm{X}$ & & $\mathrm{X}$ & $\mathrm{X}$ & & & & $\mathrm{X}$ & & & & $\mathrm{X}$ & $\mathrm{X}$ & \\
\hline $\begin{array}{l}\text { Indonesian } \\
\text { agroforests }\end{array}$ & $\mathrm{X}$ & $\mathrm{X}$ & $\mathrm{X}$ & $\mathrm{X}$ & & $\mathrm{X}$ & & $X$ & & $X$ & & $X$ & $\mathrm{X}$ & \\
\hline Gascogne & $\mathrm{X}$ & $\mathrm{X}$ & $\mathrm{X}$ & & & & & & $\mathrm{X}$ & & $\mathrm{X}$ & $\mathrm{X}$ & & $\mathrm{X}$ \\
\hline $\begin{array}{l}\text { Pyrenees } \\
\text { ash tree }\end{array}$ & & $\mathrm{X}$ & $\mathrm{X}$ & & $\mathrm{X}$ & & & & & & & $\mathrm{X}$ & & \\
\hline $\begin{array}{l}\text { Corsica } \\
\text { chestnut }\end{array}$ & $\mathrm{X}$ & $\mathrm{X}$ & $\mathrm{X}$ & $\mathrm{X}$ & & & & $\mathrm{X}$ & $\mathrm{X}$ & & $\mathrm{X}$ & $\mathrm{X}$ & & $\mathrm{X}$ \\
\hline $\begin{array}{l}\text { Cevennes } \\
\text { chestnut }\end{array}$ & $\mathrm{X}$ & $\mathrm{X}$ & $\mathrm{X}$ & $\mathrm{X}$ & & & & $\mathrm{X}$ & $\mathrm{X}$ & & $\mathrm{X}$ & $\mathrm{X}$ & & $X$ \\
\hline $\begin{array}{l}\text { Truffle } \\
\text { Languedoc }\end{array}$ & & & $X$ & & & & & & $X$ & & $X$ & $X$ & & $X$ \\
\hline $\begin{array}{l}\text { Cameroon } \\
\text { Rankin }\end{array}$ & $X$ & $X$ & $X$ & $X$ & & $X$ & & $X$ & & $X$ & $X$ & $X$ & $X$ & \\
\hline $\begin{array}{l}\text { frequency } \\
\text { of use }\end{array}$ & 3 & 4 & 1 & 4 & 7 & 8 & 9 & 4 & 7 & 6 & 5 & 2 & 7 & 7 \\
\hline
\end{tabular}

In Table 3, we listed at least 14 uses explicitly mentioned by farmers during surveys performed in the 11 study sites, demonstrating that rural forests are all multipurpose. Uses could be divided into three groups: wood harvesting linked with ligneous forest materials; other nonligneous forest products; and activities performed in forest areas. Each site showed at least 5 different types of use, while the most diversified one had 11. Collecting firewood for cooking or heating is a widespread activity, found in all 11 sites. Timber for construction material is a common harvest activity in 9 of 11 sites. Forests are also a useful resource for livestock grazing and feeding, thanks to forage resources found in the undergrowth, and tree foliage sometimes constitutes emergency forage for periods of scarcity (e.g., snowfalls in the High Atlas and severe summer droughts in the French Pyrenees). Forest resources related to human food production are an important component of rural livelihoods, providing a high diversity of fruits, nuts, leaves, roots, stems, tubers, etc. Some resources are related to specific uses, such as the argan nuts for cosmetic and food purposes (oil).

A typology of rural forests, based on multiple uses, can be drawn as follows:

1. forests used only for local purposes (e.g., the High Atlas agdal forests, Gascony small forests).
2. forests with a double function - sustaining local livelihoods through their multiple products and providing highly marketable and typical products. For example, chestnut forests, truffle-holm oak garrigues, Indian and Indonesian agroforests and Cameroon community forests sustain local livelihoods with a large diversity of products (including those arising from animal husbandry) and simultaneously produce commercial products that sustain the local economy.

As rural forests are highly diversified in terms of fragmentation, domestication and the complex overlap between collective and individual rules, their use patterns show high flexibility and strong adaptability to changes in market demand. Today, argan oil is very high in demand, leading argan forests to shift from local use to commercial use. Chestnuts, once used solely for local subsistence in remote mountainous areas, have now become a delicacy in urban areas. In the Middle Ages, truffles were known as a satanic aphrodisiac in France and banned by the church, but later became a delicacy and the most expensive NTFP in France.

Forest islands in agricultural landscapes or integrated agricultural/forest mosaics? Fragmentation and connectivity question the forestry/agriculture divide The level of species diversity, tree cover and fragmentation 
across an agricultural landscape constitute the structural components of rural forests, and a first set of characterizing variables. Situations vary from nonfragmented, highly diverse forests (tropical forests and agroforests in Indonesia and Cameroon, Indian reserved forests) to monospecific, nonfragmented forests (chestnut and argan forests, but with a highly heterogeneous tree cover for the latter); from highly fragmented woods with a relatively high species diversity fully integrated within agricultural systems (Gascony small forests) to more or less large forest patches within a wide agroforestry mosaic (sacred Indian woods); and from isolated forest patches with a low diversity (the Atlas agdal forests) to more or less scattered individual trees within an agricultural landscape (ash tree, and argan trees located respectively in grasslands and fields).

Although variables such as species diversity may be higher in tropical regions, a high diversity may also be found in the small forests of Gascony, where distribution of trees is highly fragmented, compared to more classically managed forests (Deconchat and Balent 2001). Relationships between levels of diversity and fragmentation are inherent to each situation and therefore independent from the biogeographical areas where such rural forests are located. Both fragmentation and species diversity appear to vary according to the type of agroecosystems and agricultural techniques developed over time within each region, and according to social and political factors. For example, in rural forests in tropical regions such as Cameroon, Indonesia and India, a whole range of fragmentation levels occurs: in Cameroon, the agricultural technique of shifting cultivation is adapted to the local situation where large forest tracts are still available, while in certain parts of the Indian Ghâts region, anthropogenic agroforests have almost completely replaced wild forests tracts. These shifting cultivation practices also generate forest tracts at different stages. In Indonesia, shifting cultivation has slowly given way to extensive, highly diverse agroforests, as a result of a historical transformation of shifting cultivation practices into settled and continuous farming within forests. In India, the strong influence of public forest policies has led to partitioning different types of forests, more or less integrated within rural landscapes. French rural forest cases also show very different techniques, which affect both the diversity and the level of fragmentation.

The distribution patterns of forests in rural landscapes can be grouped into four types of matrices:

1. scattered trees in open agropastoral landscapes (such as the ash tree forests in the Pyrenees in former times, or argan trees integrated within cereal cultivation areas)

2. forest patches in a global agricultural or agropastoral mosaic (small forests in Gascony, forest agdal in Morocco's High Atlas mountains or village forestgardens in Java)
3. managed human-made open forests characterized by a continuous mosaic with low and controlled tree density, sometimes with cultivated undergrowth (the argan forest, managed chestnut forest-orchards in Corsica and Cevennes, and the truffle - holm oak association)

4. dense forest matrix composed of various forest facies characterized by different structures, uses and functions (the forest mosaic of the western Ghats, agroforests in Indonesia, village forests in Cameroon).

These four situations are all on a continuum between and within each type of rural forest. In Europe, the abandonment of individual ash tree management has led to afforestation of grasslands (Pyrenees). Scattered forest patches are often connected through linear forested systems (like hedgerows in Gascony and argan forests, roads and gullies in Java), which have an essential ecological role. Forest matrices consist of a mosaic of different spaces that differ in terms of vegetation composition and structure, ecology, history, use or ownership. In Indonesian agroforest landscapes the forest matrix includes various stages of agroforest-under-construction (fallow-like vegetation enriched with useful species); mature agroforest, and high, nonappropriated forest, with a relative fluidity between these facies. In the argan forest, the mosaic comprises predominantly agricultural plots with large, scattered argan trees, adjacent to more or less closed native argan forest formations, which contribute to the local ecosystem diversity.

\section{Forest transformation or domestication}

A second set of variables that affects the structure of rural forests is related to the level of transformation of the natural forest ecosystem by human activities, which can be extended in some cases to the level of domestication.

Some cases show a very low level of transformation closely related to rural forest management approaches that assist ecosystem processes and forest dynamics through a set of technical practices and social rules (e.g., through shifting cultivation in the Cameroon case), which tends to maintain a high level of diversity.

A mixed approach can be found in the traditional Indonesian agroforests, which are composed of a mixture of domesticated and wild trees globally managed together like an 'almost natural ecosystem'. In such agroforests, felling one large tree for timber, for example, is equivalent to a forest gap provoked by a tree fallen naturally. The farmer will then either plant new trees in this forest gap, or leave it to spontaneously be colonized by seedlings from surrounding domesticated or wilder trees. A total continuity is thus established in such systems between the wild and the cultivated.

The Moroccan forest agdals, the argan forest or the ancient holm oak associations are moderately transformed forests due to animal husbandry, but also largely rely upon ecosystem processes for their regeneration. At the same time, they are 
subject to high levels of individual tree transformation (tree pruning and shaping e.g., field argan trees, and management of Mediterranean burnt areas that produce truffles around each individual tree in the holm oak associations).

A higher level of domestication is applied in highly transformed agroecosystems such as the Cevennes or Corsican chestnut forests, which are historically human-made forests and highly domesticated at the tree level, including selection of varieties over time. Yet when these agro-ecosystems are abandoned, they revert to seminatural forests of spontaneously regenerating trees. The reversible nature of rural forests is essentially linked to the nature of trees, which are resilient beyond people's domestication practices and beyond presentday generations of users. The most significant example is the ongoing process of domestication of the native rainforest in the Western Ghats in India for shade coffee cultivation where a progressive replacement of native trees by fast growing trees (silver oak) occurs discreetly. The forest canopy seems unchanged when tree diversity decreases rapidly with the intensification of coffee management practices.

Transformation or domestication levels define four major types of rural forest:

1. rural forests that are insignificantly transformed, managed at an ecosystem level and reliant on ecosystem processes. They may be part of continuous forest matrices (Cameroon) or small patches scattered within the agricultural landscape (Gascony)

2. rural forests that include highly domesticated trees (agroforests), as well as a large proportion of wild forest components which form a mosaic of different forest stages within agricultural matrices

3. rural forests that are highly transformed, mainly by animal husbandry and livelihood-related uses, and where trees are subject to variable levels of transformation or domestication including pruning and tree shaping (e.g., High Atlas, Pyrenees)

4. monospecific human-made forests such as the Cevennes or Corsican chestnut forests, which are highly transformed and domesticated and based on intraspecific variations induced by human selection over time.

\section{Access, levels of control and impact of forest policies}

Access invariably defines types and structures of rural forests and their use. Various levels of ownership, types of rules of access (and therefore responsibilities) explain the large array of situations found. Collective local rules are classically opposed to individual and more private rules (and ownership) when applied to agricultural patches (e.g., collective rice fields or private wheat fields or vineyards), but as shown by our results these types of rules overlap in the context of rural forests, independent of biogeographical regions. State policies and forms of control over forests are also usually seen as distinct from collective local rules and policies, but also significantly overlap in the context of rural forests.

In tropical rural forests (Cameroon, Indian reserved forests and Indonesian agroforests), collective local rules dominate together with individual ownership (e.g., Indonesian agroforests in Sumatra). In these agroforests, people privately own different patches, which jointly form a large domain of agroforest that remains linked to collective customary rules regarding sale, ways of using noncommercial products and access to products remaining after harvest or to fallen fruits (e.g., durian) by the poorest groups in the population. Simultaneously, the overall forest remains under the jurisdiction of the state to some extent. In the Mediterranean and temperate rural European (French) regions, forests are highly privatized, but also linked to different forms of collective rules. For example, in the Cevennes chestnut forests, the use of water and hunting are linked to collective approaches. In Corsica, trees are owned individually and are separated from the land ownership, which may belong to a group. In some situations, such as the Moroccan High Atlas Mountains, even though state forestry services exclusively manage the forests officially, forest management still largely depends upon collective rules, and highly refined decision and control structures maintain collective control over forest resources.

Finally, the cases of both the argan forests and the Indian reserved forests in particular illustrate that an overlap between local collective rules, management systems and state interventions are a major characteristic of rural forests. This overlap can be more or less conflicting, depending upon the history and how coercive forestry sectors have been in controlling forest management.

\section{DISCUSSION}

This comparative study does not result from an existing template to inventory and characterize forests that support rural livelihoods worldwide. Rather, it stems, from a desire to compare forest situations in rural setting not usually grouped together due to geographical and disciplinary silos between and within research teams. The POPULAR Project gave us the opportunity to access to detailed interdisciplinary information on a few cases; they are far from covering the tremendous diversity of situations worldwide, but were judged sufficiently diverse and representative to help us outline rural forests' identity marks. As far as we know, it's the first time that such diverse situations as tropical, temperate and semiarid forests from developing and developed countries were brought together in a common analytical grid. Other studies emphasized comparisons of particular types of forests, including mainly tropical forests (Michon et al. 2007), forest products (Ruiz-Pérez et al. 2004, Belcher and Ruiz-Pérez 
2001, Marshall et al. 2003), or regional areas (e.g., Congo Basin forest landscape for Endamana et al. 2010). These studies provided useful conceptual and methodological indications for our own work.

\section{Livelihood-sustaining services: an important function of rural forests}

The case studies illustrate that rural forests play diverse roles for local human populations who depend on forest resources. These resources include extraction and exploitation of multiple forest products, but also include social relationships, land tenure and territory control, cultural identity and the longevity of societies. That is, forests fully enter into the social construction of many local societies (Sauget 1994). Although numerous studies demonstrate that the primary role of rural forests is to sustain livelihoods (Bahuguna 2000), forestry literature seldom acknowledges the livelihood function as a fundamental way to understand how these forests function and are managed. The highly diverse services and complex properties provided by rural forests to sustain livelihoods should be globally included within a social ecological approach (Deconchat et al. 2007). Our comparative study has consequences upon how forest management is envisaged, questioning scales and timing of interventions, and their efficiency in the context of social demands framed by a given human group. Genin and Simenel (2011) illustrate how Berber peasants in the Moroccan High Atlas mountains manipulate their forest resources (from individual trees, to tree stands, and at the landscape level) to extract different goods and services; and how forested areas - such as holm oak matorrals in the High Atlas that foresters consider as nonuseful and degraded areas - can intentionally be maintained and play a key role in sustaining livelihoods.

In addition to their roles as storage for biodiversity, as regulator of water and soil flows and as important carbon sinks (Lal 2005), forests also often help sustain livelihoods. Hence, sustainable management options for these forests should better include this dimension, and adapt their methodologies and goals, particularly concerning scales of perception (beyond the tree stand), participatory and concerted approaches, as well as tools of evaluation.

Playing and dealing with forest structures and resources Professional forestry commonly perceived indigenous forest management as primarily firewood extraction, and therefore deigns to call it 'management' (Cinotti and Normandin 2002). Examples given in this paper, and in others (Colfer and Byron 2001), show that, in reality, local forests usually exhibit properties that result from clear multipurpose management options and patterns. This does not necessarily mean these management systems are always ecologically sound, but they are at least intentionally implemented with a focus on mediumterm sustainability. The processes that sustain these rural forests -what Michon and de Foresta (1999) have called 'forest preference'- while favoring a small number of species, usually intentionally emphasize heterogeneity and respect global forest structures, functions and services over time and space (Garcia-Fernandez et al. 2003). As Michon et al. (2007) stated: 'Management and design practices include a mix of intention and intervention (planting, clearing, pruning) and "respectful friendship" or "connivance" (integrating these intervention practices into natural processes in order to take full advantage of them) with a touch of "laisser-faire" (letting things happen as long as they are not considered as harmful for the socialecological system)'.

Temporality and spatiality are central to rural forest management: they are fully integrated into decision-making options for the use of local resources, following a holistic approach aiming at purveying and securing resources necessary for livelihoods at any time during the year. This often leads to spatial and temporal manipulation, and use of diversified forest resources, ensuring a continuous overall productivity throughout the year. Michon et al. (2007) offered several valuable insights into the temporal cycles involved in traditional establishment and use of forest trees and products in Indonesia, with the cases of benzoin and rubber forests. we show this characteristic is common to all types of rural forests. It also shows the uniqueness of each situation, which varies according to specific agroecosystems, techniques, historical and policy backgrounds.

Classical forest management plans usually ignore, and sometimes intentionally impede, compatibility with the cycles of rural activities. In classical forestry, for example, a common complete clear cut for timber is generally followed by a long fallow period (which can last several decades) to allow the tree stand to regenerate. Farmers' ideas for tree regeneration and management can be very different, and integrated within continuous productive exploitation, as illustrated by practices in West African agroforest parks (Petit 2003), in the small forests of Gascony, in the French chestnut forests, or in the wooded fields of the Moroccan Argan forest region. The various situations described in these last two case studies demonstrate that forest structures are highly variable and reversible in space and time; these structures include hedgerows, abandoned trees and integrated agrosilvopastoral activities, as well as tree reproduction integrating both vegetative and sexual reproduction (Aumeeruddy-Thomas et al. 2012, Genin and Simenel 2011). Respect for temporalities and cycles of rural activities in traditional forest management is, in our opinion, critical for renewing concerted forest and territory management approaches.

\section{A specific balance between 'nature' and 'culture', and domestication processes at various scales}

Domestication in rural forests does not only refer to the conventional patterns of tree selection and ecosystem simplification that characterize domestication in horticulture, 
in industrial forestry, or in intensive agroforestry. It also refers to specific practices targeting natural trees or ecosystem structure, to the links between forests and domestic units and to the incorporation of human and social dimensions into forest design (which does not exclude selection process or deep transformations of tree populations) (Wiersum 1997).

Domestication in rural forest can be obvious. The chestnut culture of Cevennes or Corsica are good examples, which developed hundreds of varieties by grafting, produced specific ecosystem structures and landscapes, and constituted the foundation of a culture known as the 'chestnut civilization'. But domestication in rural forests is most often invisible. In the small forests of Gascony, for example, local management practices helped constitute an original pool of diversified genetic resources of in four coexisting oak tree species. These species increase the adaptability and resilience of the forest stands to ongoing local climatic events and long-term changes (Lepais et al. 2006).

Domestication in rural forests therefore consists of a subtle, constantly evolving compromise between 'nature' and 'humanity' to find complementary processes between natural dynamics and artificial efforts. This perpetual balance between natural processes and human technical controls constitutes one of the main structuring features of a rural forest's identity. It also forms an important factor in its resilience (Cenkl 2010).

\section{Complex access systems with overlapping state and customary control}

One of the main factors structuring access is the combination of forest ownership and forest management, and more specifically, the confrontation between legal forestry frameworks and local forest management (Sandberg 2007). This confrontation is more or less universal, as national forestry frameworks are often poorly compatible with local forest practices and organizations (Fairhead and Leach 1996). This does not necessarily lead to explicit conflicts, but it does incite a variety of situations that reflect diverse socio-historical linkages between local farmers and state authorities.

The strict partition between 'state' and 'private' forest management is often bypassed by either state decisions or local practices (Peluso 1996). Rural forests therefore develop in a complex legal framework where state regulations, local customary systems, and de facto practices overlap; this can lead to conflict, resistance, manipulation or destruction, as well as to arrangements, cooperation, incorporation or hybridization of forestry legislations and customary regulations (Aubert et al. 2009). In India, under a regime called Joint Forest Management, rural people are 'invited' to participate in forest management, but under state conditions and norms. In Cameroon, community forestry approaches follow the same 'top-down' patterns, but because of the absence of state agents in villages, people are more or less free to pursue their own forest management patterns. In the
Moroccan High Atlas, where forests belong to the state and are theoretically managed by forestry administration, rural communities have historically been, and still are, the real managers of forests surrounding villages. The overlapping of customary rights and legal frameworks also occurs in developed countries. The management of chestnut trees and lands in Corsica, for example, follows a customary, anticonstitutional regime that dissociates rights on the land and rights on the trees: trees can be planted on someone else's land (including on the commons) and remain the private property of the planter and his or her heirs, even when the land is transferred or alienated (Michon and Sorba 2010).

Hence, the numerous ongoing initiatives (Larson et al. 2010) to promote 'rapprochement' between forest ownership and forest management views, will only improve local development and environmental conservation, if they appreciate the complexity implied in forest land tenure and management interactions, and integrate the points of view of the various stakeholders, and particularly local populations. This surely demands extended consultation, leading perhaps to changing laws and adopting innovative governance schemes such as territory charts (Dereix 2008).

\section{CONCLUSION}

The terminology of rural forest we propose here wants to be a unified concept embracing the various terms previously employed to describe a specific category of forest management which clearly differs from classic professional forestry both in terms of structures and functions, and in terms of uses and governance.

It results from a study that has put together and analyzed the similarities and specificities between a range of rural forests that had never been compared because their respective ecological, sociocultural, economic and political perspectives apparently lay too far apart. We analyzed their characteristics through a global approach embracing ecological, economic and socio cultural components. Very few methodologies to achieve this goal are available and they have some weaknesses, particularly when a diversity of highly heterogeneous variables is under consideration (quantitative, qualitative, interpretative, dynamic, static, etc.). With our aim to detect the general outlines of a rural forest, the challenge was to integrate representative cases from diverse situations even though they represent a very small sample of what could be called a rural forest.

In this innovative attempt to develop formal evidence of the specificities of rural forests, we highlighted their multifunctional dimensions: their long-term usefulness for extracting goods, accommodating livelihoods, and taking control of landscapes and territories, while being intimately linked to local culture and knowledge. Diversity characterizes rural forests, which are distributed among large categories depending on level of fragmentation, tree density, 
biogeographical situations, sociopolitical context and social organization. Such interactions between nature and culture result in local identities built upon, and through, the complex relationships between forest and agriculture. Rural forests result from a constant and dynamic multifaceted shaping and from multiple-scale domesticating processes. These are undertaken in light of the need for rural societies to satisfy their economy and perpetuate their culture, and in a context of relatively adverse policies and misunderstandings. Their multipurpose products and flexible spatial and temporal management are very valuable assets in the context of global change; they constitute a highly diversified pool of resources and ecosystems, potentially useful to the resilience of forest ecosystems all over the world.

Given their vital role in sustaining livelihoods and promoting ecosystem adaptations, rural forests should be considered as models for forestry development within rural set-ups. Four characteristics define the typologies of these models:

- their structure and levels of integration into agricultural mosaics in relation to agro ecosystem practices, along with their historical development.

- the multi scale approach of domestication practices from ecosystem to individual trees inscribed in continuities between natural processes and human techniques of control as well as social practices.

- their uses in relation to the commercial or noncommercial status of their products, and the reversible nature of these use patterns, including associated exchange or commercial circuits.

- the overlap between and among access, state and customary control and, individual and collective rules, requiring specific arrangements.

Responses to this article can be read online at: http://www.ecologyandsociety.org/issues/responses. php/5429

\section{Acknowledgments:}

This study was conducted within the research program POPULAR : 'Public Policies and Farmers' Local Management of Trees and Forests: Sustainable Alliance or Foul's Dialogue?" funded by the French National Research Agency (ANR-06-PADD-014). It is based on detailed monographs and data provided by the teams and researchers involved in this program including. M. Alifriqui, L. Auclair, A. Cabanettes, M. Deconchat, C. Garcia, A. Gavaland, S. Guillerme, C. Hinnewinkel, S. Ladet, G. Lescuyer, G. Michon, $B$. Romagny, and R. Simenel who contributed to these monographs and for their thoughtful discussions in the elaboration of the data. This work would not have been possible without their valuable contributions. We address a special thanks to G. Michon for her significant input to the first draft of the present paper. We also thank local partners and all members of local communities who have spent much time with us on the field or during indoor discussions which enabled us to disentangle the complexities of their rural forests. Finally we extend our thanks to Karin Holzknecht who has helped with the final edition of this manuscript, and to two anonymous Reviewers who have, undoubtedly, helped to improve our statements.

\section{LITERATURE CITED}

Angelsen, A., H. Asbjornsen, B. Belcher, G. Michon, and M. Ruiz-Pérez. 2000. Cultivating (in) tropical forests? The evolution and sustainability of intermediate systems between extractivism and plantations. in $\mathrm{H}$. Asbjornsen, A. Angelsen, B. Belcher, G. Michon, M. Ruiz-Pérez, and V. P. R. Wijesekara, editors. Proceedings of the international workshop: Cultivating (in) Tropical Forests. Lofoten, Norway.

Aubert, P. M., M. Leroy, and L. Auclair. 2009. Moroccan forestry policies and local forestry management in the High Atlas: a cross analysis of forestry administration and local institutions. Small Scale Forestry 8: 175-191. http://dx.doi. org/10.1007/s11842-009-9076-4

Auclair, L., P. Baudot, D. Genin, B. Romagny, and R. Simenel. 2011. Patrimony for resilience: evidence from the forest Agdal in the Moroccan High Atlas Mountains. Ecology and Society 16(4): 24. http://dx.doi.org/10.5751/ES-04429-160424

Aumeeruddy-Thomas, Y., C. Therville, C. Lemarchand, A. Lauriac, and F. Richard. 2012. Resilience of sweet chestnut and truffle holm-oak rural forests in Languedoc-Roussillon, France: roles of social-ecological legacies, domestication, and innovations. Ecology and Society 17(2): 12. http://dx.doi. org/10.5751/ES-04750-170212

Bahuguna, V. K. 2000. Forest in the economy of the rural poor: an estimation of the dependency level. Ambio 29: 126-129.

Balent, G. 1996. La forêt paysanne dans l'espace rural: biodiversité, paysages, produits. INRA Editions, Paris, France.

Belcher, B., and M. Ruiz-Pérez. 2001. An international comparison of cases of forest product development: overview, description and data requirements. CIFOR Working Paper Number 23. CIFOR, Bogor, Indonesia.

Benzecri, J. P. 1973. L'analyse des données. Dunod Editons, Paris, France. http://dx.doi.org/10.2333/bhmk.10.14 1

Cenkl, P. 2010. Nature and Culture in the Northern Forest: Region, Heritage, and Environment in the Rural Northeast. University of Iowa Press, Iowa City, USA. 
Cinotti, C., and D. Normandin. 2002. Farmers and forest property - What has happened to the "peasant forest"? Revue Forestière Française LIV (4): 311-328.

Colfer, C. J. P., and Y. Byron. 2001. People managing forests: the links between human well being and sustainability. RFF Press, Washington DC, USA.

Deconchat, M., and G. Balent. 2001. Vegetation and bird community dynamics in fragmented coppice forests. Forestry 74:105-118. http://dx.doi.org/10.1093/forestry/74.2.105

Deconchat, M., A. Gibon, A. Cabanettes, G. du Bus de Warnaffe, M. Hewison, E. Garine, A. Gavaland, J.-P. Lacombe, S. Ladet, C. Monteil, A. Ouin, J.-P. Sarthou, A. Sourdril, and G. Balent. 2007. How to set up a research framework to analyze social-ecological interactive processes in a rural landscape. Ecology and Society 12(1): 15. [online] URL: http://www.ecologyandsociety.org/vol12/iss1/art15/.

Descola, P. 1986. La Nature Domestique: Symbolisme et praxis dans l'écologie des Achuar. Edition Maison des Sciences de l'Homme, Paris, France.

Dereix, C. 2008. L'approche territoriale de la gestion forestière ; une plus-value pour la qualité des paysages. Revue Forestière Française 60(5) : 525-531.

Endamana, D., A. K. Boedhihartono, B. Bokoto, L. Defo, A. Eyebe, C. Ndikumegenge, Z. Nzooh, M. Ruiz-Pérez, and J. Sayer. 2010. A framework for assessing conservation and development in a Congo Basin forest landscape. Tropical Conservation Science 3(3): 262-281.

Fairhead, J., and M. Leach. 1996. Rethinking the forest savanna mosaic. Colonial science and its relics in West Africa. in $\mathrm{M}$. Leach and $\mathrm{R}$ Means, editors. The lie of the land. Challenging receive wisdom on the African environment. James Curry, Oxford, UK.

Feintrenie, L., S. Schwarze, and P. Levang. 2010. Are local people conservationists? Analysis of transition dynamics from agroforests to monoculture plantations in Indonesia. Ecology and Society 15(4): 37. [online] URL: http://www. ecologyandsociety.org/vol15/iss4/art37/.

Garcia-Fernandez, C., M. A. Casado, and M. Ruiz-Pérez. 2003. Benzoin gardens in North Sumatra, Indonesia: effects of management on tree diversity. Conservation Biology 17: 828-836.http://dx.doi.org/10.1046/j.1523-1739.2003.01487. $\mathrm{x}$

Genin, D., Y. Aumeerudy-Thomas, G. Balent, and G. Michon. 2010. A framework for characterizing convergence and discrepancy in rural forest management in tropical and temperate environments. in IUFRO Proceedings of Landscape Ecology International Conference, 21-27 September. Bragança, Portugal.
Genin, D., and R. Simenel. 2011. Endogenous Berber management and the shaping of rural forests in Southern Morocco: implications for shared forest management options. Human Ecology 39: 257-269. http://dx.doi.org/10.1007/ $\underline{\text { s10745-011-9390-2 }}$

Hammi, S., V. Simonneaux, J. B. Cordier, D. Genin, M. Alifriqui, N. Montes, and L. Auclair. 2010. Can traditional forest management buffer forest depletion? Dynamics of Moroccan High Atlas Mountain forests using remote sensing and vegetation analysis. Forest Ecology and Management 260: 1861-1872. http://dx.doi.org/10.1016/j.foreco.2010.08.033

Heckenberger, M. J., A. Kuikuo, U. Tabat Kuikuro, J. C. Russell, M. Schmidt, C. Fausto, and B. Franchetto. 2003. Amazonia 1492: pristine forest or cultural parkland? Science 301: 1710-1714.

Hinnewinkel, C., S. Guillerme, and A. Menon. 2008. Diversity of rural forests in central western Ghâts (India): views from different stakeholders. Pages 105-116 in Proceedings of the IUFRO International Symposium, Small-scale rural forest use and management: global policies vs. local knowledge. Nancy, France.

Julien, M. P., D. Alard, and G. Balent. 2006. Patterns of ash (Fraxinus excelsior L. ) colonization in mountain grasslands: the importance of management practices. Plant Ecology 183: 177-189.

Lal, R. 2005. Forest soils and carbon sequestration. Forest Ecology and Management 220: 242-258. http://dx.doi. org/10.1016/j.foreco.2005.08.015

Larson A., D. Barry, G. Ram Dahal, and C. J. P. Colfer. 2010. Forests for people: community rights and forest tenure reform. Earthscan Publ., London. 263p.

Lepais, O., J. Lavabre,M. Gonzalez, J. Willm, A. Cabanettes, and S. Gerber. 2006. Diversité et structuration génétique des chênes à l'échelle de deux paysages: impact de l'écologie, de l'histoire et de la gestion. Les Actes du BRG 6: 543-557.

Lescuyer, G., S. Assembe Mvondo, J. N. Essoungou, V. Toison, J.-F. Trébuchon, and N. Fauvet. 2012. Logging concessions and local livelihoods in Cameroon: from indifference to alliance? Ecology and Society 17(1): 7. http:// dx.doi.org/10.5751/ES-04507-170107

Macura, B., F. Zorondo-Rodríguez, M. Grau-Satorras, K. Demps, M. Laval, C. A. Garcia, and V. Reyes-García. 2011. Local community attitudes toward forests outside protected areas in India. Impact of legal awareness, trust, and participation. Ecology and Society 16(3): 10. http://dx.doi. org/10.5751/ES-04242-160310

Marshall, E., A. C. Newton, and C. Schrekenberger. 2003. Commercialization of Non-Timber Forest Products. First 
steps in analyzing the factors influencing success. International Forestry Review 5(2): 128-137.

Michon, G. 2011. Revisiting the resilience of chestnut forests in Corsica: from social-ecological systems theory to political ecology. Ecology and Society 16(2): 5. [online] URL: http:// www.ecologyandsociety.org/vol16/iss2/art5/

Michon, G., and H. de Foresta. 1999. Agroforests: incorporating a forest vision in agroforestry. Pages 281-406 in L. E. Buck, J. Lassoie, and E. C. M. Fernandes, editors. Agroforestry in sustainable agricultural systems. CRC Press, Washington DC, USA.

Michon, G., H. De Foresta, P. Levang, and F. Verdeaux 2007. Domestic forests: a new paradigm for integrating local communities' forestry into tropical forest science. Ecology and Society 12(2): 1. [online] URL: http://www. ecologyandsociety.org/vol12/iss2/art1/

Michon, G., and J. Sorba. 2010. I trè Valli: Passer par-dessus les montagnes. Ethnologie Française 38: 465-477.

Nasi, R., G. Michon, and G. Balent. 2013. Public policies and management of rural forests: lasting alliance or fool's dialogue? Ecology and Society Special Feature 62. [online] URL: http://www.ecologyandsociety.org/issues/view.php? $\underline{\mathrm{sf}=62}$.

Ni Dhubhain, A., M. Fléchard, R. Moloney, and D. O'Connor. 2009. Stakeholders' perceptions of forestry in rural areas two case studies in Ireland. Land Use Policy 26: 695-703.

Peluso, N. L. 1996. Fruit trees and family trees in an anthropogenic forest: ethics, access, property zones, and environmental change in Indonesia. Comparative studies in Society and History 38: 510-548. http://dx.doi.org/10.1017/ S0010417500020041

Petit, S. 2003. Parklands with fodder trees: a Fulbe response to environmental and social changes. Applied Geography 23: 205-225.

Pretzsch, J. 2005. Forest related rural livelihood strategies in national and global development. Forests, Trees and Livelihoods 15: 115-127. http://dx.doi.org/10.1080/147280$\underline{28.2005 .9752515}$

Ruiz-Pérez, M., B. Belcher, R. Achdiawan, M. Alexiades, C. Aubertin, J. Caballero, B. Campbell, C. Clement, T. Cunningham, A. Fantini, H. de Foresta, C. García Fernández, K. H. Gautam, P. Hersch Martínez, W. de Jong, K. Kusters, M. G. Kutty, C. López, M. Fu, M. A. Martínez Alfaro, T. R. Nair, O. Ndoye, R. Ocampo, N. Rai, M. Ricker, K. Schreckenberg, S. Shackleton, P. Shanley, T. Sunderland, and Y. Youn. 2004. Markets drive the specialization strategies of forest peoples. Ecology and Society 9(2): 4. [online] URL: http://www.ecologyandsociety.org/vol9/iss2/art4/.
Sandberg, A. 2007. Property rights and ecosystem properties. Land Use Policy 24: 613-623. http://dx.doi.org/10.1016/j. landusepol.2006.01.002

Sauget, N. 1994. Of land, woods and men: farmers talk about the land, the evolution of woodland areas and the landscape. Landscape Issues 11: 52-58.

Simenel, R., G. Michon, L. Auclair, B. Romagny, Y. Thomas, and M. Guyon. 2009 Argan: l'huile qui cache la forêt domestique. De la valorisation des produits à la naturalisation de l'écosystème. Autrepart 50: 51-74.

Sourdril, A., E. Andrieu, A. Cabanettes, B. Elyakime, and S. Ladet. 2012. How to maintain domesticity of usages in small rural forests? Lessons from forest management continuity through a French case study. Ecology and Society 17(2): 6. http://dx.doi.org/10.5751/ES-04746-170206

Wiersum, K. F. 1997. Indigenous exploitation and management of tropical forest resources: an evolutionary continuum in forest-people interactions. Agriculture, Ecosystems and Environment 63: 1-16. http://dx.doi. org/10.1016/S0167-8809(96)01124-3 
Appendix 1: Rates of the outcomes for each variable characterising rural forest case studies, following 'forest groups' and 'variables classes' provided by the Hierarchical Cluster Analysis. Mean value of a determined variable class: in red, means that it is significantly under $(<2)$ the average; in bold, means that it is significantly above (>3.4) the average.

\begin{tabular}{|c|c|c|c|c|c|c|c|c|c|c|c|c|}
\hline Groups & & 1 & & 2 & & 3 & & 4 & & & 5 & \\
\hline Variables & Class & $\begin{array}{c}\text { Morrocan } \\
\text { Forest } \\
\text { Agdals } \\
\end{array}$ & $\begin{array}{l}\text { Indonesian } \\
\text { Agroforest }\end{array}$ & $\begin{array}{c}\text { Cameroon } \\
\text { comunitary } \\
\text { forest }\end{array}$ & $\begin{array}{l}\text { Indian } \\
\text { Forest } \\
\text { reserve }\end{array}$ & $\begin{array}{c}\text { Indian } \\
\text { Agroforest }\end{array}$ & $\begin{array}{l}\text { Argan } \\
\text { Forest }\end{array}$ & $\begin{array}{l}\text { Corsican } \\
\text { Chestnut }\end{array}$ & $\begin{array}{l}\text { Cevennes } \\
\text { Chestnut }\end{array}$ & Gascony & $\begin{array}{c}\text { Ash Tree } \\
\text { (Pyrenees) }\end{array}$ & $\begin{array}{c}\text { Truffle- } \\
\text { oak Forest }\end{array}$ \\
\hline $\begin{array}{l}\text { Non formal collective } \\
\text { actions }\end{array}$ & 1 & 2 & 2 & 3 & 3 & 1 & 3 & 4 & 3 & 3 & 2 & 2 \\
\hline $\begin{array}{l}\text { Fodder } \\
\text { Transformation of forest }\end{array}$ & 1 & 5 & 1 & 1 & 5 & 3 & 5 & 4 & 4 & 2 & 4 & 3 \\
\hline $\begin{array}{l}\text { products } \\
\text { Valorization of forest }\end{array}$ & 1 & 1 & 1 & 3 & 3 & 2 & 5 & 5 & 3 & 2 & 4 & 2 \\
\hline $\begin{array}{l}\text { products } \\
\text { Transformations of the }\end{array}$ & 1 & 1 & 1 & 3 & 2 & 2 & 5 & 5 & 5 & 1 & 2 & 4 \\
\hline social systems & 1 & 3 & 2 & 2 & 3 & 2 & 3 & 4 & 4 & 3 & 4 & 1 \\
\hline Mean & & 2,4 & 1,4 & 2,4 & 3,2 & 2 & 4,2 & 4,2 & 3,8 & 2,2 & 3,2 & 2,4 \\
\hline $\begin{array}{l}\text { stands } \\
\text { Domestication of }\end{array}$ & 2 & 4 & 3 & 1 & 2 & 5 & 5 & 5 & 5 & 4 & 2 & 3 \\
\hline $\begin{array}{l}\text { landscape } \\
\text { Fragmentation of forests }\end{array}$ & 2 & 5 & 2 & 1 & 2 & 5 & 5 & 5 & 5 & 5 & 5 & 3 \\
\hline in the landscape & 2 & 3 & 1 & 1 & 2 & 2 & 1 & 1 & 1 & 5 & 4 & 5 \\
\hline Private landownership & 2 & 1 & 3 & 1 & 1 & 5 & 3 & 4 & 4 & 5 & 5 & 5 \\
\hline $\begin{array}{l}\text { Influence individual actors } \\
\text { New actors not from } \\
\text { Sustainable Development }\end{array}$ & 2 & 1 & 3 & 1 & 2 & 5 & 3 & 5 & 5 & 5 & 5 & 5 \\
\hline $\begin{array}{l}\text { sector } \\
\text { Regards by the users of }\end{array}$ & 2 & 1 & 1 & 1 & 1 & 3 & 1 & 2 & 3 & 3 & 4 & 2 \\
\hline $\begin{array}{l}\text { the restriction of use } \\
\text { Functions of territory } \\
\text { marking and land }\end{array}$ & 2 & 2 & 2 & 1 & 3 & 2 & 3 & 4 & 4 & 5 & 4 & 5 \\
\hline appropriation & 2 & 4 & 5 & 1 & 1 & 5 & 4 & 2 & 2 & 3 & 4 & 5 \\
\hline
\end{tabular}


Traditional Knowledge on tree stand management

\section{Mean}

Level of Transformation of the natural ecosystem

Domestication of trees

Importance of tourism in

rural forest

Commercial functions

Identity function

Traditional Knowledge on

individual trees

management

Organisational knowledge

Political knowledge

Increase in forest surfaces

Dynamics in the practices observed

Integration forest/other

activities

\section{Mean}

Stability of the ecosystem multi-use of forest

Timber harvesting

Firewood harvesting

self-consumption or use

Patrimonial functions

Stakes in the construction of the territories

\begin{tabular}{|c|c|c|c|c|c|c|c|c|c|c|c|}
\hline 2 & 4 & 2 & 2 & 1 & 4 & 3 & 2 & 4 & 5 & 1 & 4 \\
\hline & 2,8 & 2,4 & 1,1 & 1,7 & 4 & 3,1 & 3,3 & 3,7 & 4,1 & 3,8 & 4,1 \\
\hline 3 & 2 & 4 & 2 & 2 & 4 & 3 & 5 & 5 & 2 & 4 & 3 \\
\hline 3 & 2 & 3 & 1 & 1 & 4 & 3 & 5 & 5 & 2 & 4 & 2 \\
\hline 3 & 1 & 1 & 1 & 2 & 4 & 4 & 5 & 3 & 2 & 3 & 1 \\
\hline 3 & 1 & 5 & 4 & 2 & 5 & 4 & 5 & 5 & 2 & 2 & 5 \\
\hline 3 & 3 & 4 & 3 & 3 & 5 & 5 & 5 & 5 & 3 & 3 & 2 \\
\hline 3 & 4 & 3 & 2 & 1 & 4 & 5 & 5 & 5 & 2 & 5 & 3 \\
\hline 3 & 5 & 3 & 3 & 2 & 3 & 3 & 5 & 4 & 2 & 2 & 3 \\
\hline 3 & 1 & 3 & 2 & 3 & 5 & 3 & 5 & 4 & 2 & 2 & 3 \\
\hline 3 & 1 & 3 & 2 & 1 & 4 & 1 & 5 & 3 & 2 & 1 & 2 \\
\hline 3 & 2 & 3 & 4 & 1 & 4 & 4 & 5 & 4 & 1 & 4 & 4 \\
\hline 3 & 3 & 4 & 3 & 3 & 3 & 3 & 5 & 4 & 2 & 2 & 3 \\
\hline & 2,3 & 3,3 & 2,5 & 1,9 & 4,1 & 3,5 & 5 & 4,3 & 2 & 2,9 & 2,8 \\
\hline 4 & 2 & 4 & 5 & 4 & 1 & 3 & 3 & 3 & 5 & 5 & 2 \\
\hline 4 & 4 & 5 & 5 & 4 & 4 & 5 & 4 & 4 & 5 & 4 & 3 \\
\hline 4 & 2 & 4 & 4 & 2 & 4 & 1 & 1 & 2 & 3 & 2 & 1 \\
\hline 4 & 5 & 3 & 2 & 5 & 5 & 4 & 3 & 3 & 4 & 3 & 3 \\
\hline 4 & 5 & 4 & 5 & 5 & 5 & 4 & 2 & 2 & 4 & 5 & 4 \\
\hline 4 & 5 & 5 & 3 & 2 & 5 & 5 & 5 & 5 & 5 & 3 & 5 \\
\hline 4 & 4 & 4 & 5 & 5 & 5 & 5 & 5 & 4 & 4 & 3 & 3 \\
\hline
\end{tabular}


Ancianity of the use

\section{Mean}

Level of tree cover

New speakers from

Sustainable Development

sector

Non Timber Forest

Products

Exogenous new practices

Biodiversity stakes

\section{Mean}

Diversity of tree species

Collective ownership

State ownership

Influence of traditional

collective institutions in

forest management

Existence of rules

established at the

collective level

Control level of collective

rules

Importance of agriculture

in forest

Sacred functions

Functions of

reserves/security

Naturalist knowledge

mobilized in forest

\begin{tabular}{|c|c|c|c|c|c|c|c|c|c|c|c|}
\hline 4 & 5 & 5 & 3 & 4 & 2 & 5 & 5 & 5 & 5 & 5 & 4 \\
\hline & 4 & 4,3 & 4 & 4 & 4 & 4 & 3,5 & 3,5 & 4,4 & 3,8 & 3,1 \\
\hline 5 & 1 & 5 & 5 & 5 & 4 & 4 & 4 & 4 & 1 & 1 & 3 \\
\hline 5 & 3 & 4 & 4 & 4 & 2 & 5 & 3 & 4 & 1 & 2 & 4 \\
\hline 5 & 1 & 5 & 5 & 5 & 3 & 5 & 5 & 5 & 3 & 4 & 5 \\
\hline 5 & 1 & 4 & 3 & 3 & 2 & 5 & 1 & 3 & 1 & 3 & 4 \\
\hline 5 & 3 & 5 & 5 & 5 & 5 & 4 & 3 & 4 & 3 & 4 & 4 \\
\hline & 1,8 & 4,6 & 4,4 & 4,4 & 3,2 & 4,6 & 3,2 & 4 & 1,8 & 2,8 & 4 \\
\hline 6 & 2 & 5 & 5 & 5 & 4 & 1 & 1 & 1 & 4 & 1 & 2 \\
\hline 6 & 5 & 4 & 5 & 2 & 1 & 4 & 2 & 1 & 1 & 1 & 1 \\
\hline 6 & 5 & 5 & 5 & 5 & 1 & 4 & 1 & 2 & 1 & 1 & 2 \\
\hline 6 & 5 & 4 & 4 & 3 & 1 & 4 & 1 & 1 & 1 & 1 & 1 \\
\hline 6 & 5 & 5 & 4 & 3 & 1 & 5 & 3 & 3 & 1 & 1 & 2 \\
\hline 6 & 5 & 4 & 4 & 3 & 1 & 4 & 2 & 2 & 1 & 1 & 1 \\
\hline 6 & 1 & 4 & 4 & 1 & 5 & 4 & 1 & 1 & 1 & 1 & 1 \\
\hline 6 & 3 & 1 & 4 & 3 & 1 & 4 & 1 & 1 & 1 & 1 & 1 \\
\hline 6 & 5 & 4 & 4 & 2 & 4 & 3 & 2 & 3 & 1 & 1 & 3 \\
\hline 6 & 3 & 4 & 5 & 1 & 2 & 3 & 2 & 3 & 2 & 1 & 4 \\
\hline
\end{tabular}




\section{management}

Traditional knowledge in

landscape management Regression of forest

surfaces

Integration

forest/agriculture

Economic stakes

Mean

Explicit conflicts between policies and local actors Place of State in forest

management

Restriction of the rights of

the users by the State

Control level of national

rules

Erosion and water

conservation stakes

Social stakes

\begin{tabular}{|c|c|c|c|c|c|c|c|c|c|c|c|}
\hline 6 & 4 & 3 & 4 & 1 & 2 & 5 & 2 & 3 & 2 & 1 & 1 \\
\hline 6 & 4 & 3 & 2 & 2 & 1 & 1 & 2 & 2 & 1 & 1 & 1 \\
\hline 6 & 4 & 4 & 5 & 2 & 5 & 5 & 3 & 3 & 2 & 1 & 1 \\
\hline 6 & 3 & 5 & 5 & 2 & 5 & 5 & 3 & 3 & 2 & 1 & 3 \\
\hline & 4 & 4 & 4,3 & 2,5 & 2,4 & 3,7 & 1,9 & 2,1 & 1,5 & 1 & 1,7 \\
\hline 7 & 5 & 4 & 2 & 4 & 4 & 5 & 3 & 2 & 1 & 1 & 2 \\
\hline 7 & 3 & 5 & 3 & 5 & 3 & 4 & 2 & 3 & 1 & 3 & 2 \\
\hline 7 & 4 & 4 & 3 & 5 & 3 & 3 & 1 & 1 & 1 & 1 & 2 \\
\hline 7 & 3 & 3 & 2 & 5 & 4 & 3 & 1 & 1 & 2 & 1 & 1 \\
\hline 7 & 5 & 3 & 2 & 5 & 5 & 5 & 3 & 3 & 3 & 1 & 3 \\
\hline 7 & 5 & 5 & 4 & 5 & 5 & 5 & 5 & 4 & 3 & 2 & 2 \\
\hline & 4,2 & 4 & 2,7 & 4,9 & 4 & 4,2 & 2,5 & 2,3 & 1,8 & 1,5 & 2 \\
\hline
\end{tabular}

Mean 